\title{
Analysis of FMRF-Amide Effects on Aplysia Bursting Neurons
}

\author{
Peter Ruben, Jon W. Johnson, and Stuart Thompson \\ The Hopkins Marine Station of Stanford University, Pacific Grove, California 93950
}

\begin{abstract}
The peptide L-phenylalanyl-L-methionyl-L-arginyl-L-phenylalaninamide (FMRF-amide) was pressure-applied onto the somata of bursting neurons $\mathrm{L}_{4}$ and $\mathrm{L}_{6}$ in the Aplysia abdominal ganglion. FMRF-amide causes a biphasic response, first depolarizing and then hyperpolarizing the neuron. In voltage-clamp experiments, FMRF-amide induces an inward current that begins 100-200 msec after applying the peptide and peaks in 210 sec. This is followed by an outward current that begins with a latency of 2-5 sec and peaks in 15-65 sec. The entire response lasts 1-5 min. Experiments were done to separate the two currents induced by FMRF-amide on the basis of ion selectivity and kinetics and to determine their $I(V)$ relationships. The currents were studied using a method to quickly measure $I(V)$ curves. The inward current is caused by a conductance increase and has a reversal potential of approximately $+18 \mathrm{mV}$. This current depends on the concentration of extracellular $\mathrm{Na}$ ions but not $\mathrm{Ca}, \mathrm{Cl}$, or $\mathrm{K}$ ions and is insensitive to tetrodotoxin, hexamethonium, and curare. The outward current is caused by a conductance increase and has a reversal potential of approximately $-61 \mathrm{mV}$, which is similar to the reversal potential of the fast, transient $K$ current $\left(I_{A}\right)$ in the same cells. This current is sensitive to changes in the external $K$ ion concentration but not to changes in $\mathrm{Cl}, \mathrm{Ca}$, or $\mathrm{Na}$ concentration. The outward current is partially blocked by $1 \mathrm{mM}$ 4-aminopyridine but not TEA or curare. Neither current is significantly voltage dependent within the range from -70 to $-40 \mathrm{mV}$.
\end{abstract}

These data indicate that, in these neurons, FMRF-amide activates two separate types of ion channels. The likelihood that FMRF-amide acts as a transmitter or hormone in Aplysia is strengthened by these observations. The ionic mechanisms characterized here can lead to potent modulation of bursting pacemaker neurons by an endogenous peptide.

There are numerous examples of small peptides that modify the activity of central neurons as well as glandular and muscle cells (Kreiger, 1983; Walther et al., 1984). The neuroactive peptide L-phenylalanyl - L-methionyl - L - arginyl - L-phenylalaninamide (FMRF-amide) was first described as a cardiac exciter in the clam Macrocallista nimbosa by Price and Greenberg (1977). Cottrell (1982) and co-workers (1984) showed that FMRF-amide has two effects on the giant serotonergic neuron in the snail Helix, where the peptide both induced a K current at the resting potential and reduced a $\mathrm{Ca}$ - and voltage-dependent $\mathrm{K}$ current at more depolarized voltages.

In the mollusc Aplysia californica, immunoreactivity to FMRF-amide has been demonstrated in the abdominal ganglion

\footnotetext{
Received June 3, 1985; revised July 15, 1985; accepted July 17, 1985.

The authors thank Brad Jones and Julie Coombs for discussions and critical review of the manuscript, and Stacey Davis for participation in an early phase of the work. This work was supported by a grant from the Alberta Heritage Foundation for Medical Research to P.R., and U. S. P. H. S. grants to S.T. (NS 14514) and J.W.J. (MH 09113).

Correspondence should be sent to Peter Ruben, Bekesy Laboratory, University of Hawaii, 1993 East-West Road, Honolulu, HI 96822.

Copyright (C) 1986 Society for Neuroscience $0270-6474 / 86 / 010252-08 \$ 02.00 / 0$
}

(Brown et al., 1984) and in neurons innervating the gill musculature (Weiss et al., 1984). It has been shown that this immunoreactivity is due specifically to FMRF-amide and not to other related peptides (Lehman et al., 1984). Stone and Mayeri (1981) reported on the effects of FMRF-amide on identified neurons of Aplysia and showed that the peptide produces inhibition in some cells $\left(L_{2}, L_{3}, L_{4}, L_{6}, L_{10}\right)$ and biphasic excitationinhibition in others $\left(\mathrm{L}_{1}, \mathrm{R}_{1}\right)$. These studies imply that FMRFamide is an endogenous neuroactive substance in Aplysia.

In this paper we report on the effects of FMRF-amide on two bursting pacemaker neurons, $\mathrm{L}_{4}$ and $\mathrm{L}_{6}$, in the Aplysia abdominal ganglion. These two cells are easily identified and their electrophysiological properties are similar. We observed that the response to FMRF-amide was qualitatively the same in $\mathrm{L}_{4}$ and $L_{6}$. By studying identified cells, the variability in response properties that occurs between different cell types is avoided. These bursting neurons have been extensively studied and are important model systems for paccmaker activity in neurons. Study of the hormonal regulation of bursting neurons provides further insight into the kinds of processes that can modulate neuronal pacemakers. FMRF-amide modifies the firing properties of $\mathrm{L}_{4}$ and $\mathrm{L}_{6}$ by causing an initial depolarization, often accompanied by action potentials, followed by hyperpolarization and silencing of the cell. In voltage-clamp experiments, pressure application of FMRF-amide onto the surface of the cell body causes a biphasic current response when the cell voltage is held within the pacemaker voltage range. An inward current develops within $100 \mathrm{msec}$ after applying the peptide and peaks in 2-10 sec. The membrane current then gradually becomes outward, and this outward current peaks in 15-65 sec followed by a slow decline. The entire response lasts $1-5 \mathrm{~min}$. The current can be separated into two components on the basis of ionic selectivity and kinetics. A preliminary report of this work has appeared elsewhere (Ruben et al., 1984).

\section{Materials and Methods}

Aplysia californica were obtained from Sea Life Supply (Sand City, CA) and were kept in flowing unfiltered seawater at ocean temperature (11$15^{\circ} \mathrm{C}$ ). The abdominal ganglion was removed and pinned to the Sylgard base of a Lucite chamber that had a fluid capacity of $2 \mathrm{ml}$. The ganglion was manually desheathed without enzyme treatment, and in certain cases the left upper quadrant cells were axotomized by a transverse section across the left side of the ganglion and undercutting with iris scissors. $\mathrm{L}_{4}$ or $\mathrm{L}_{6}$ was identified by position, size, color, and bursting activity pattern (Frazier et al., 1967; Koester and Kandel, 1977). The cell was impaled with two glass microelectrodes filled with $3 \mathrm{M} \mathrm{KCl}$ or 2 м KAc (resistance, 3-7 M $\Omega$ ). The choice of anion had no effect on the results.

FMRF-amide (Sigma) was applied locally to the soma from a glass micropipette with an orifice diameter of approximately $3 \mu \mathrm{m}$ by a pressure pulse (20-65 psi; durations 20-700 msec) from a Picospritzer II (General Valve Corp., Hanover, NJ). The delivery pipette was positioned as close as possible to the cell body without actually penetrating the cell. The pipette contained a $1 \mathrm{~mm}$ or $10 \mu \mathrm{M}$ solution of FMRFamide dissolved in artifical seawater or the appropriate experimental medium ( $10 \mu \mathrm{M}$ in all experiments shown in figures).

Cells were bathed in an artificial seawater (ASW) consisting of 476 


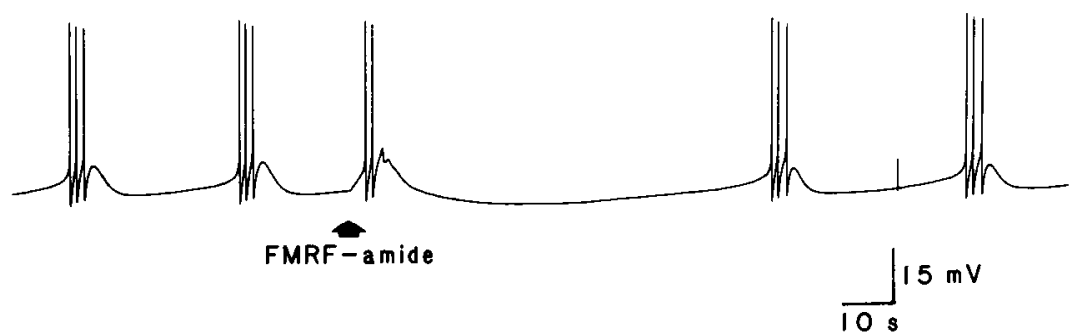

Figure 1. Biphasic response to FMRF-amide. Record of bursting activity in $\mathbf{L}_{6}$ showing interruption of normal rhythmic activity on FMRFamide applications. After pressure application of the peptide to the soma, the cell is initially depolarized, resulting in two spikes out of phase with previous bursting. Thereafter, the cell becomes hyperpolarized for a more prolonged period than the normal interburst interval. mм NaCl, 10 mм KCl, 10 mм CaCl, 24 mм $\mathrm{MgCl}_{2}, 29$ mм $\mathrm{MGSO}_{4}$, buffered with $2 \mathrm{mM}$ HEPES to a pH of 7.6. Zero-sodium seawater was made by substituting Tris- $\mathrm{Cl}, N$-methyl-D-glucamine, or $\mathrm{LiCl}$ for $\mathrm{NaCl}$. Two kinds of Ca-free media were used. One of these contained $6 \mathrm{mM}$ $\mathrm{MgCl}_{2}$ and $2 \mathrm{mM} \mathrm{NiCl}$ in place of $10 \mathrm{mM} \mathrm{CaCl}_{2}$. The other contained $4 \mathrm{~mm}$ EGTA and $10 \mathrm{mM} \mathrm{CoCl}_{2 x}$ in place of $\mathrm{CaCl}_{2}$. Low-chloride seawater was prepared by equimolar substitution of $476 \mathrm{~mm} \mathrm{Na-isethionate} \mathrm{for}$ $\mathrm{NaCl}$ to lower the final $\mathrm{Cl}$ concentration to $83 \mathrm{~mm}$, or $209 \mathrm{~mm} \mathrm{Na}_{2} \mathrm{SO}_{4}$ for $\mathrm{NaCl}$ to lower the final chloride concentration to $136 \mathrm{~mm}$. Solution changes were made by perfusing the bath with at least $10 \times$ the bath volume. In some experiments the bath was continually perfused during peptide application. Bath temperature was controlled at $11-14^{\circ} \mathrm{C}$. Tetraethylammonium (TEA), tetrodotoxin (TTX), $d$-tubocurarine, and hexamethonium were obtained from Sigma; 4-aminopyridine (4-AP) was from Aldrich Pharmaceutical Company, Inc.

Voltage-clamp experiments used standard two-microelectrode techniques as described by Barish and Thompson (1983). Membrane current was measured using either a virtual ground circuit or a voltage clamp applied to the bath. Signals were low-pass-filtered by an active filter with corner frequency selected between 20 and $2000 \mathrm{~Hz}$.

The magnitude and reversal potential of the currents induced by FMRF-amide were determined using a low-noise method for quickly measuring current-versus-voltage $(I(V))$ curves (Johnson and Thompson, 1983). Cell voltage was stepped through a staircase pattern beginning at $-40 \mathrm{mV}$ and progressing in $5 \mathrm{mV}$ intervals to $-80 \mathrm{mV}$. Each step lasted $20 \mathrm{msec}$. The associated membrane current was low-passfiltered at $500 \mathrm{~Hz}$, digitized at $4 \mathrm{kHz}$, and recorded during this sequence of voltages by computer (DEC 11/23). To reduce noise, 6-12 msec of current data at each voltage were averaged. This average was not started until the current stopped changing after each voltage step. The filtered capacitive transient settled to less than $1 \%$ of its peak value in about 2 msec. In the -40 to $-80 \mathrm{mV}$ range the current continued to decay slowly for another 6-12 msec, probably due to incomplete cell isolation: Axonal membrane capacitance would be expected to charge relatively slowly due to axonal resistance. The current average, therefore, began 8 to $14 \mathrm{msec}$ after each voltage step and extended to the end of the step at $20 \mathrm{msec}$. A line was fitted by the method of least squares to the points used to calculate the current average. Data were accepted if the slope of this line was not significantly different from zero as judged by a $t$ test. With this method a nine-point $I(V)$ curve, which can resolve a change in resting cell conductance of less than $10 \%$, can be generated in $180 \mathrm{msec}$.

Each $I(V)$ curve represents the sum of all the conductances active between -40 and $-80 \mathrm{mV}$ during its measurement. To measure the change due to FMRF-amide an $I(V)$ curve measured before FMRFamide application is subtracted from an $I(V)$ curve measued at various times during the FMRF-amide response. Any conductance not affected by FMRF-amide is eliminated by the subtraction. The result of this subtraction is an $I(V)$ curve for the FMRF-amide response alone. Since the conductances activated by the peptide are not significantly voltage dependent and change very little during the time needed to measure the $I(V)$ curve, the difference $I(V)$ curve is effectively an instantaneous measure of the FMRF-amide-induced conductance change. The slope of the difference $I(V)$ curve indicates whether there is a conductance increase or decrease and the magnitude of the change. A positive slope indicates a conductance increase and a negative slope indicates a conductance decrease. The point at which the difference $I(V)$ curve crosses the voltage axis gives the reversal potential of the current at the time of the measurement. This is the true reversal potential if only a single conductance is activated. If there is more than one type of conductance change during the $I(V)$ curve measurement, the voltage where the current equals zero is a weighted sum of the reversal potentials of the component currents. Some difference $I(V)$ curves did not cross the voltage axis within the measured voltage range. In these cases, the reversal potentials were estimated by extrapolation of a line fitted by the method of least squares to the data. Such extrapolations are expected to give a reasonable approximation of the reversal potential because the conductances activated by FMRF-amide do not appear to be significantly voltage dependent in the measured voltage range, as shown by the linearity of the difference $I(V)$ curves. Extrapolations were not accepted if the fitted lines had a correlation coefficient $(R)$ less than 0.9 . Less than $25 \%$ of all fits were rejected. For $82 \%$ of the accepted $I(V)$ curves the $R$ value exceeded 0.98 . Reversal potentials of currents suspected to be $\mathrm{K}$-dependent were compared to the reversal potential of a known $\mathrm{K}$ current, $I_{A}$, measured in the same cell (Thompson and Aldrich, 1980). $I_{A}$ was activated by a voltage step to $-20 \mathrm{mV}$ following a 500 msec conditioning prepulse to $-90 \mathrm{mV}$. At the peak of $I_{A}$ the voltage was stepped to various levels to find the reversal potential for the rapidly decaying $I_{A}$ tail current.

\section{Results}

\section{Biphasic response to $F M R F$-amide}

Several neurons in the left upper quadrant of the Aplysia abdominal ganglion characteristically exhibit rhythmic pacemaker firing activity. The cells we studied, $\mathrm{L}_{4}$ and $\mathrm{L}_{6}$, typically fire 24 spikes in a burst with bursts recurring every 5-40 sec. Pressure application of FMRF-amide onto the cell body of $\mathrm{L}_{4}$ or $\mathrm{L}_{6}$ at any point in the activity cycle results in a rapid depolarization that can give rise to $1-5$ spikes followed by a gradually developing hyperpolarization that exceeds the hyperpolarization normally seen during the interval between bursts (Fig. 1).

The response to FMRF-amide was studied in voltage-clamp experiments. When the neuron is held at $-40 \mathrm{mV}$, pressure application of FMRF-amide onto the cell body produces a biphasic current response (Fig. 2). Within 100-200 msec after applying the peptide, an inward current is activated that peaks in $8.4 \mathrm{sec}$ (average time to peak $=6.1 \mathrm{sec} \pm 1.8 \mathrm{SD}, n=5$ ). This is followed by the gradual development of an outward current that reaches a peak in $50.7 \mathrm{sec}$ (average time to peak = $34 \sec \pm 24 \mathrm{SD}, n=5$ ). The entire response lasts $1-5 \mathrm{~min}$. The duration of the response is slightly decreased when peptide ejection is accompanied by continuous-bath perfusion. The latency and time course of the current were not significantly changed after decreasing ejection time by a factor of $10(200-20 \mathrm{msec})$ and increasing the concentration of peptide in the pipette by a factor of $100(10 \mu \mathrm{M}-1 \mathrm{mM})$. Increasing ejection time alone resulted in increased response magnitude. The time course and amplitude of the inward and outward currents are sufficient to explain the biphasic FMRF-amide responses in unclamped cells.

There was considerable variation in the amplitude of the FMRF-amide response in different cells, although the biphasic form of the response was consistently observed. Often, the response amplitude changed little throughout the course of an experiment, but in some cases, the response amplitude decreased during repeated applications and remained small despite wash with ASW. In such cases, the inward response was usually seen to decrease more quickly than the outward response. Moving the FMRF-amide pipette to a different area of the cell resulted in recovery of the response amplitude. 
Figure 2. Membrane current elicited by FMRF-amide. Record of current with cell voltage clamped at 40 $\mathrm{mV}$ showing the biphasic response to FMRF-amide. An inward current is produced with a short latency after FMRF-amide is applied to the soma of $L_{6}$. This is followed by an outward current of greater amplitude and duration.

The voltage dependence of the response to FMRF-amide was studied by holding the cell at a series of different voltages from -70 to $-30 \mathrm{mV}$ and applying the peptide with a constant pressure pulse (Fig. 3). As the holding potential was moved in the depolarizing direction from $-40 \mathrm{mV}$, the ampltiude of the inward current early in the response decreased, while the later outward current increased. A reversal potential was not established for the inward current because prolonged depolarization above $-30 \mathrm{mV}$ activates large ionic currents that lead to irreversible damage to the cell. When the holding potential was moved in the hyperpolarizing direction, the outward current late in the FMRF-amide response decreased and reversed when the cell was held at $-70 \mathrm{mV}$. The inward current amplitude increased as the cell was hyperpolarized. The time course of the response changed little over this voltage range. Peak inward current and current measured near the time of the peak outward current ( $65 \mathrm{sec}$ after peptide application) from the data shown on the left in Figure 3 were used to plot $I(V)$ curves. These curves are shown in the top graph in Figure 3.

The lower graph in Figure 3 shows data collected from the same cell using the staircase voltage sequence and subtraction procedure, described in Materials and Methods, to measure $I(V)$ curves at the time of peak inward and peak outward current. Both the inward and the outward currents result from conductance increases, as shown by the positive slopes of the difference $I(V)$ curves. An advantage of this method for measuring $I(V)$ curves is that one or several $I(V)$ curves can be gathered during a single peptide application. Noise due to variation in response amplitude is therefore eliminated. This is especially important for responses that desensitize during repeated applications of peptide.
$I(V)$ curves measured in another cell are shown in Figure 4. The $I(V)$ curve measured at the peak of the inward current is shown by the solid line. Linear extrapolation of this line to the voltage axis gives an estimated reversal potential $\left(V_{\text {rev }}\right)$ of +23 $\mathrm{mV}$. The average estimated reversal potential at the peak of the inward current response is $+18 \mathrm{mV}( \pm 13 \mathrm{mV} \mathrm{SD}, n=9)$. The $I(V)$ curve measured at the peak of the outward current during the same FMRF-amide application is shown by the dashed line in Figure 4. The current has a reversal potential $\left(V_{\text {rev }}\right)$ of -62 $\mathrm{mV}$. The average reversal potential at the peak of the outward current response is $-61 \mathrm{mV}( \pm 7 \mathrm{mV} \mathrm{SD}, n=20)$. This value is close to the average reversal potential of $-62 \mathrm{mV}( \pm 5 \mathrm{mV}$ $\mathrm{SD}, n=12$ ) for transient $\mathrm{K}$ current, $I_{A}$, measured in the same cells.

\section{Inward response}

The positive reversal potential for the inward current early in the response to FMRF-amide suggests that $\mathrm{Na}$ and/or $\mathrm{Ca}$ ions may be important charge carriers. Figure 5 shows the results of an experiment in which $\mathrm{Na}$ was replaced by Tris in the cxternal medium. The inward current is absent in the Na-free medium, as shown by the current records in the inset. The difference $I(V)$ curves show substantial conductance increase in the control measurement (solid line), no significant conductance change in Tris (dashed line), and partial recovery in the wash (dotted line). The inset shows that when normal ASW is reintroduced, the inward current partially recovers. Tris partly blocks inward current channels activated by acetylcholine (Ascher et al., 1978), so Tris may not be entirely satisfactory as a $\mathrm{Na}$ replacement. The inward current was also absent in seawater in which $\mathrm{NaCl}$ was replaced with $N$-methyl-D-glucamine and the current re-
Figure 3. Biphasic response at different holding potentials. Lefi, Currents induced by FMRF-amide are shown for cell clamped at different holding voltages. Time of peptide application indicated by the arrow. Right, Upper graph shows the $I(V)$ relationship for inward current (solid line) and outward current (dashed line) of raw data shown to the left. Inward current was measured at its peak. Outward current was measured at 65 sec. The $I(V)$ curve for outward current crosses the voltage axis at -62 $\mathrm{mV}$. Extrapolation of the $I(\mathrm{~V})$ curve for inward current gives an apparent reversal potential of $+27 \mathrm{mV}$.

Lower graph shows the $I(V)$ relationship determined by the fast, staircase voltage method in the same cell. The $I(V)$ curve for outward current (dashed line) crosses the voltage axis at $-66 \mathrm{mV}$. Extrapolation of the $I(V)$ curve for the inward current gives an apparent reversal potential of +11 mV.
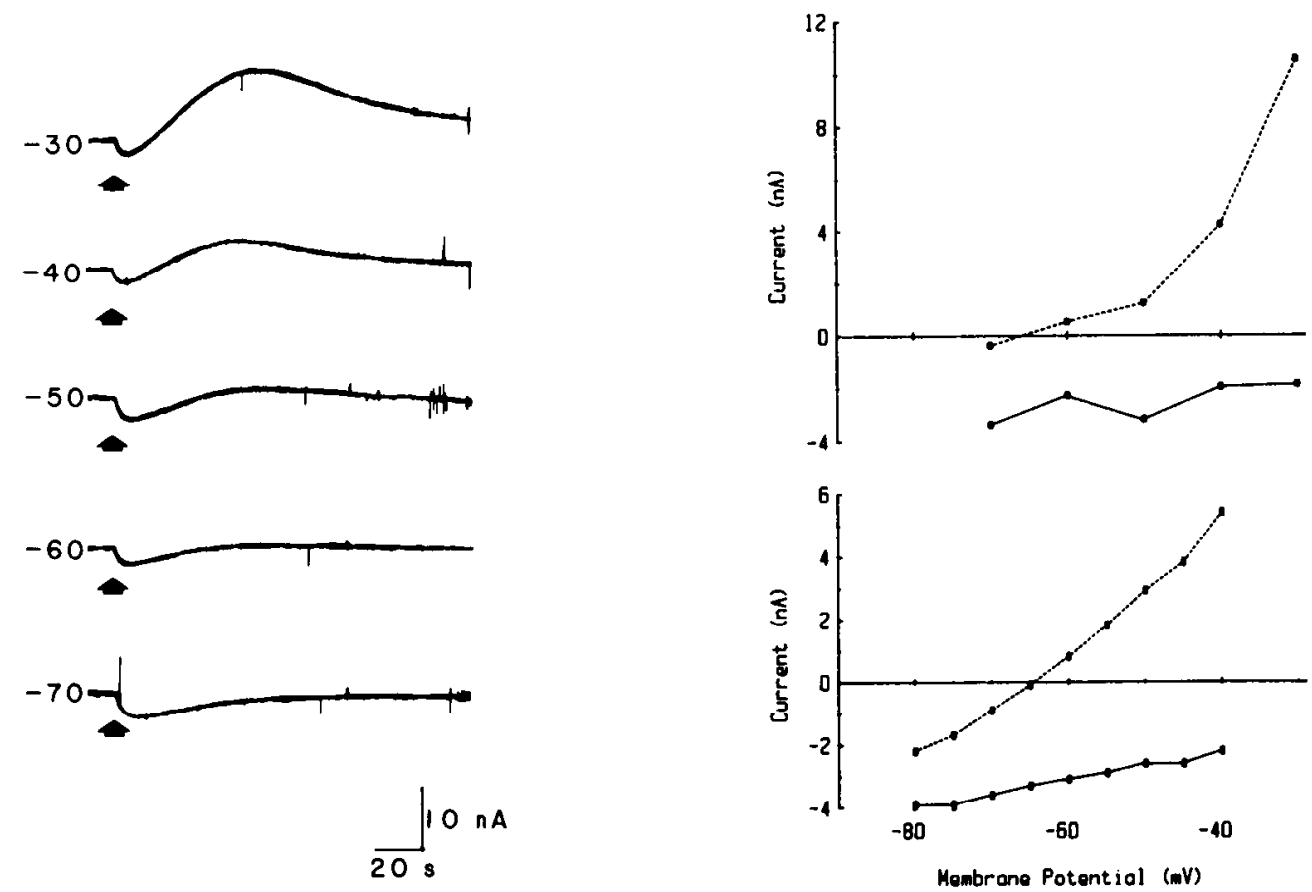
covered when $\mathrm{Na}$ was reintroduced. $\mathrm{Li}$ was observed to carry the inward current after $\mathrm{NaCl}$ had been totally replaced with $\mathrm{LiCl}$. These data indicate that $\mathrm{Na}$ makes a major contribution to the inward current during the FMRF-amide response.

The average reversal potential of $+19 \mathrm{mV}$ for the inward current is less than the value of about $+85 \mathrm{mV}$ predicted for the equilibrium potential $\left(E_{\mathrm{Na}}\right)$ from measurement of the intracellular and extracellular $\mathrm{Na}$ activity in Aplysia neurons (Cooke et al., 1974). The reversal potential for the inward current induced by FMRF-amide is in good agreement with the reversal potential for an inward current induced by acetycholine (Ascher et al., 1978), where K permeability was found to account in part for the discrepancy between $V_{\mathrm{rev}}$ and $E_{\mathrm{Na}}$. If $\mathrm{K}$ ions contribute to the FMRF-amide-induced inward current, then changing the external $\mathrm{K}$ concentration should change the apparent reversal potential of the inward current. Figure 6 shows difference $I(V)$ curves measured during the rising phase of the inward response in three different $\mathrm{K}$ concentrations. The extrapolated reversal potentials are: $+16 \mathrm{mV}$ in $2 \mathrm{~mm} \mathrm{~K} ;+28 \mathrm{mV}$ in $10 \mathrm{~mm} \mathrm{~K} ;+12$ $\mathrm{mV}$ in $50 \mathrm{~mm} \mathrm{~K}$. These values are not significantly different from the average reversal potential observed in normal seawater. The different position of the $I(V)$ curve measured in 10 $\mathrm{mM} \mathrm{K}$ indicates that the current was larger in this case, probably because it was the first FMRF-amide application in this experment. Although extrapolation magnifies measurement uncertainty, the similarity of the reversal potentials in 2 and $50 \mathrm{~mm}$ $\mathrm{K}$ argues against a significant $\mathrm{K}$ current early in the response. The resolution of these experiments is not adequate to eliminate a minor contribution from $\mathrm{K}$ current or some other ionic current. It is also possible that the difference between the extrapolated reversal potential for the inward response and $E_{\mathrm{Na}}$ may be due to rectification in the current-voltage relationship.

\section{Outward response}

The negative reversal potential for current measured at the peak of the outward response to FMRF-amide suggests that $\mathrm{K}$ may be a major charge carrier. The reversal potential of the outward current in different external $\mathbf{K}$ concentrations was determined from $I(V)$ curves measured at the peak of the outward response $40 \mathrm{sec}$ after applying the peptide. The change in reversal potential of the outward current was compared with changes in the reversal potential of a known $\mathrm{K}$ current, $I_{A}$, in the same cells. In the example shown in Figure 7, the reversal potential for the outward current response to FMRF-amide is $-55 \mathrm{mV}$ in ASW. The bath was then perfused with low ( $2 \mathrm{mM}) \mathrm{K}$ seawater. Subsequent FMRF-amide application causes the familiar biphasic response, but the amplitude of the outward current is greater than the control. The reversal potential in low $\mathrm{K}$ is $-74 \mathrm{mV}$. When the cell was bathed in a high $(50 \mathrm{~mm}) \mathrm{K}$ medium, the current due to FMRF-amide was inward at the $-40 \mathrm{mV}$ holding voltage. The estimated reversal potential in $50 \mathrm{mM} \mathrm{K}$ is -23 $\mathrm{mV}$. The reversal potentials for $I_{A}$ measured in normal and lowand high-K seawater in the same experiment are $-62,-74$, and $-37 \mathrm{mV}$, respectively. Although these data suggest that there may be some difference in the ionic selectivity of $I_{A}$ and the FMRF-amide-induced outward current, $K$ appears to be the primary charge carrier responsible for the outward current induced by FMRF-amide.

\section{Other ions and channel blockers}

The importance of $\mathrm{Cl}$ and $\mathrm{Ca}$ ions as possible charge carriers in the FMRF-amide currents was tested in ion replacement experiments. When the external medium is changed to a zero-Ca solution containing $10 \mathrm{~mm}$ Co and $4 \mathrm{~mm}$ EGTA, FMRF-amide application results in the same biphasic response as in normal ASW. A further change to a medium containing $8 \mathrm{mM} \mathrm{Mg}$ and $2 \mathrm{mM} \mathrm{Ni}$ in place of $10 \mathrm{mM} \mathrm{CaCl}_{2}$ also has no effect on the biphasic response to FMRF-amide. We conclude that the am-

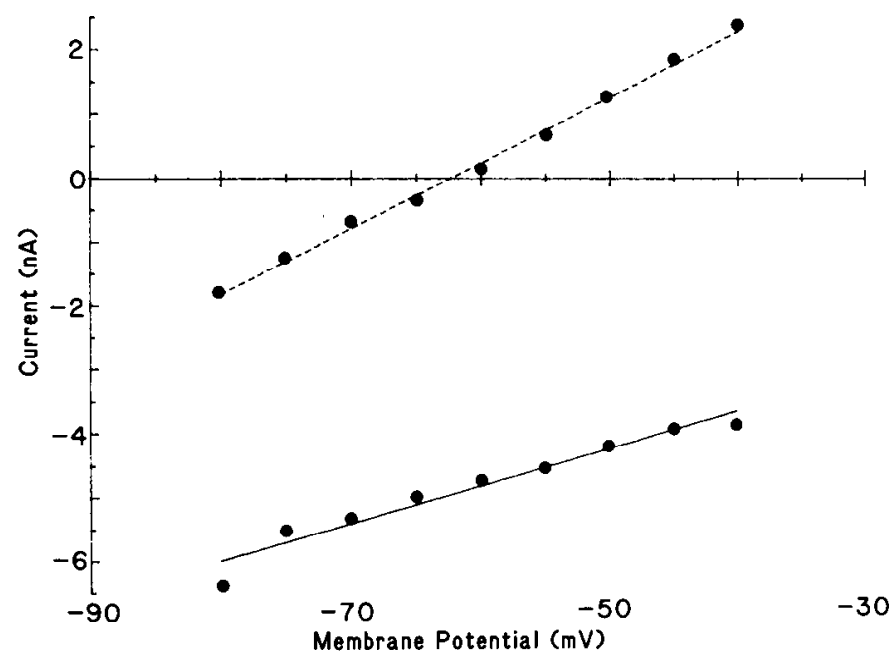

Figure 4. Difference $I(V)$ curves measured at the time of the inward current peak (solid line) and at the time of the outward current peak (dashed line) induced by FMRF-amide (different cell than shown in Fig. 3). The positive slopes of the lines indicate that the currents are due to conductance increases. Reversal potential for the inward current is estimated to be $+23 \mathrm{mV}$ and that for the outward current is $-62 \mathrm{mV}$.

plitudes and reversal potentials of the inward and outward currents are not scnsitive to external $\mathrm{Ca}$.

Rapid $\mathrm{Cl}$ currents are part of a multiphasic response induced by ACh in Aplysia neurons of the pleural and abdominal ganglia (Kehoe, 1972a, c). Chloride was not important in the action of FMRF-amide. The reversal potentials of both the inward and outward currents did not change within cxperimental error when $\mathrm{Cl}$ was replaced with $\mathrm{SO}_{4}$ or isethionate. We observed no consistent effects on the amplitude of the FMRF-amide currents when the $\mathrm{Cl}$ concentration was decreased by $75-85 \%$.

Two antagonists of ACh excitatory responses, hexamethonium and curare (Kehoe, 1972b), had no effect on the inward FMRF-amide response. Curare also blocked a fast inhibitory $\mathrm{Cl}$ conductance induced by $\mathrm{ACh}$ in Aplysia neurons (Kehoe, 1972a). Curare had no effect on the outward current caused by FMRF-amide. The sensitivity of the FMRF-amide response to $\mathrm{Na}$ and $\mathrm{K}$ channel blockers was studied using tetrodotoxin, TEA, and 4-AP. Tetrodotoxin $(10 \mu \mathrm{M})$ blocked the fast, voltage-dependent $\mathrm{Na}$ current but had no effect on the Na-dependent current caused by FMRF-amide. The outward current produced by FMRF-amide was unaffected by $100 \mathrm{~mm}$ TEA, which blocked the voltage-dependent delayed outward current. Another K channel blocker, $4-\mathrm{AP}$, caused a $40-90 \%$ reduction in the outward current in response to FMRF-amide at a concentration of $1 \mathrm{mM}$ (Fig. 8). This concentration blocked $50-100 \%$ of $I_{A}$ in the same cells.

\section{Temporal resolution of two components}

The mixed nature of the FMRF-amide response prevents direct observation of the time course of inward current decay or outward current activation. We attempted to separate the two currents using $I(V)$ curves measured at short intervals throughout a single response. The principal advantage of this method is that the time course of inward and outward currents can be measured during a single peptide application, thus avoiding complications due to desensitization inherent in other methods of separation. After the end of each $I(V)$ curve measurement, cell voltage is returned to $-40 \mathrm{mV}$ from $-80 \mathrm{mV}$. This unavoidably results in a small $(\sim 1 \mathrm{nA})$ activation of $I_{A}$. In order to prevent one $I(V)$ measurement from affecting the next, a delay $(1.5-2 \mathrm{sec})$ sufficient to allow complete decay of $I_{A}$ is made between each $I(V)$ curve measurement. The need to use a delay betwen mea- 


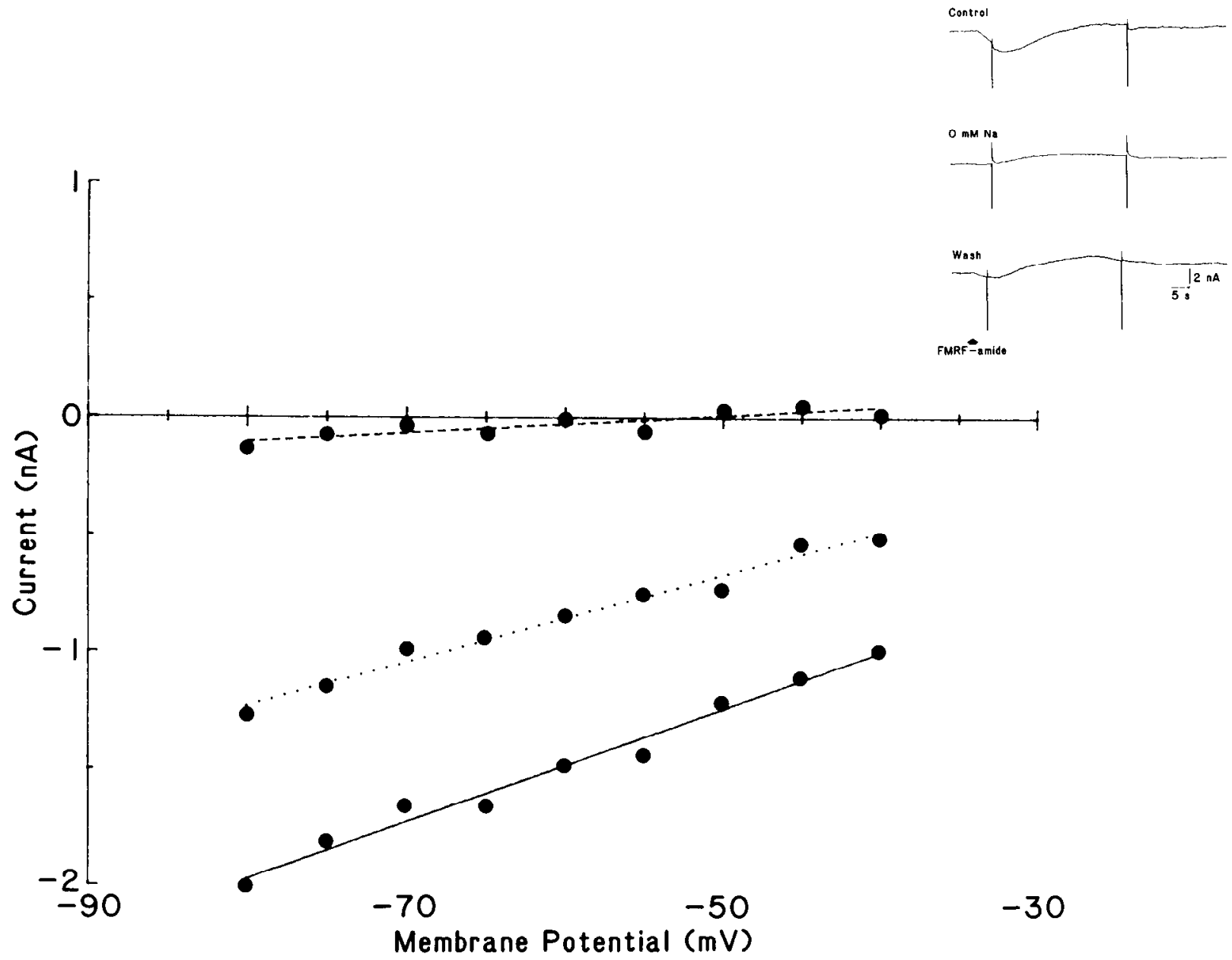

Figure 5. Effect of Na removal on the inward current. Difference $I(V)$ curves measured 3 sec after FMRF-amide application in normal ASW (solid line) and in zero- $\mathrm{Na}$ seawater (dashed line; Tris-Cl replaces $\mathrm{NaCl}$ ). In control seawater the extrapolated reversal potential was approximately $+2 \mathrm{mV}$. In zero Na there was no significant conductance change. After seawater wash (dotted line), the FMRF-amide response partially recovered to a conductance increase with an estimated reversal potential of $-13 \mathrm{mV}$. Inset, Current records during FMRF-amide applications in normal and zero-Na ASW. Vertical breaks in records indicate point at which $I(V)$ curves were measured. The data derived from these $I(V)$ curves were used to plot the lines shown.

surements prevents clear resolution of the peak of the inward FMRF-amide response, but the decay of the inward current is resolved. One such experiment is shown in the inset in Figure 9.

The reversal potentials derived from the earliest and latest $I(V)$ curves are assumed to represent the actual reversal potential for pure inward and pure outward responses. For the inward current, this assumption is based on the observation that in zero-Na seawater there is a delay of 2-5 sec before the onset of the outward component. For the outward current, the assumption is supported by the fact that the reversal potential measured at different times late in the response is the same even though the response is decaying. This indicates that late in the response there is no longer a combination of currents with different reversal potentials. Each difference $I(V)$ curve measured throughout the FMRF-amide response is fitted by the method of least squares with an equation of the form

$$
I_{M}=g_{M}\left(V-V_{M}\right)
$$

where $I_{M}$ is the measured current (in $\mathrm{nA}$ ) at membrane voltage $V$ (in $\mathrm{mV}$ ), $g_{M}$ is the conductance (in $\mu \mathrm{S}$ ), and $V_{M}$ is the reversal potential (in $\mathrm{mV}$ ) for the current. Each fitted $I(V)$ curve is the sum of two component $I(V)$ curves described by equations of the same form. The component $I(V)$ curves are assigned the reversal potentials of the inward and outward responses, determined as described above. Solving the equations for inward and outward current at $-40 \mathrm{mV}$ gives:

$$
\begin{aligned}
& I_{1}=\frac{g_{M}\left(V_{M}-V_{2}\right)\left(V_{1}+40\right)}{V_{2}-V_{1}} \\
& I_{2}=\frac{g_{M}\left(V_{1}-V_{M}\right)\left(V_{2}+40\right)}{V_{2}-V_{1}}
\end{aligned}
$$

where $I_{1}$ and $I_{2}$ are the current values (in nA) of the inward and outward currents, respectively, at $-40 \mathrm{mV}$, and $V_{1}$ and $V_{2}$ are the reversal potentials for the inward and outward currents. In Figure 9, the separated currents are plotted against time to show the contribution of each current to the total response. From this figure it is evident that the $\mathrm{K}$ current is slightly activated shortly after the peak of the inward response, and the Na current persists late into the response.

\section{Discussion}

We have shown that the peptide FMRF-amide activates two ionic currents when applied to the somata of bursting neurons $\mathrm{L}_{4}$ and $\mathrm{L}_{6}$ in the Aplysia abdominal ganglion. The response consists of an inward current carried principally by $\mathrm{Na}$ followed 


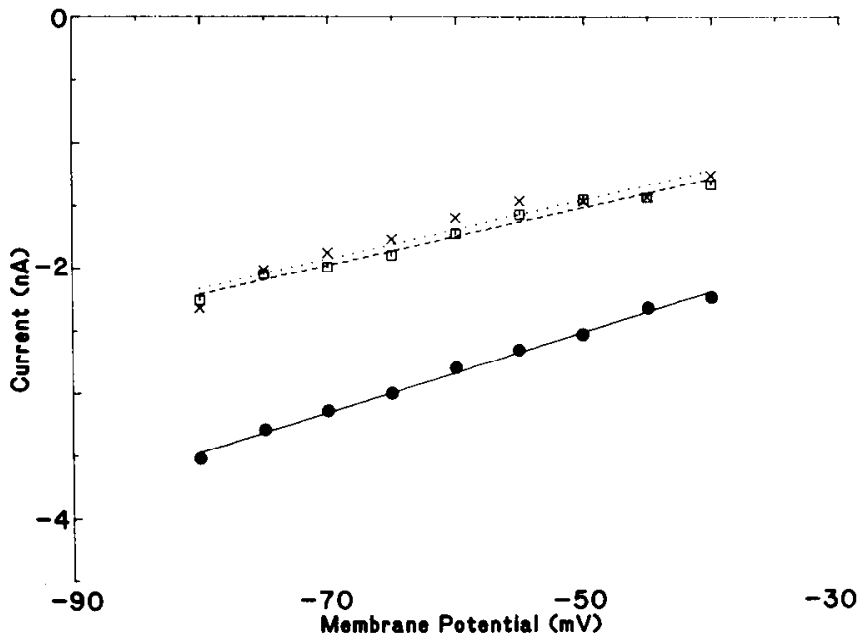

Figure 6. Effect of $\mathrm{K}$ concentration on inward current. Difference $I(V)$ curves during the inward current response measured $3 \mathrm{sec}$ after FMRFamide application at three different $\mathrm{K}$ concentrations: $10 \mathrm{~mm}$ (solid line, solid circle); $2 \mathrm{~mm}$ (dashed line, open squares); $50 \mathrm{~mm}$ (dotted line, crosses). The difference in $I(V)$ curve positions reflects variability in response amplitude. Similar extrapolated reversal potentials of +28 , +16 , and $+12 \mathrm{mV}$, respectively, indicate that $\mathrm{K}$ is not an important charge carrier during the inward response.

by a longer-lasting outward current carried principally by $\mathrm{K}$ ions. The two currents appear to involve two types of channels that can be separated on the basis of activation and recovery kinetics, ionic selectivity, and pharmacology. One type of channel is Naselective, activates rapidly after peptide application, is TTX insensitive, and selects against $\mathrm{Ca}$ but not $\mathrm{Li}$. The other type of channel is $\mathrm{K}$-selective, activates with a delay and deactivates slowly, is insensitive to TEA, and is partially blocked by 4-AP. Neither current requires Ca entry for its activation.

The latency between FMRF-amide appliation and the ap-

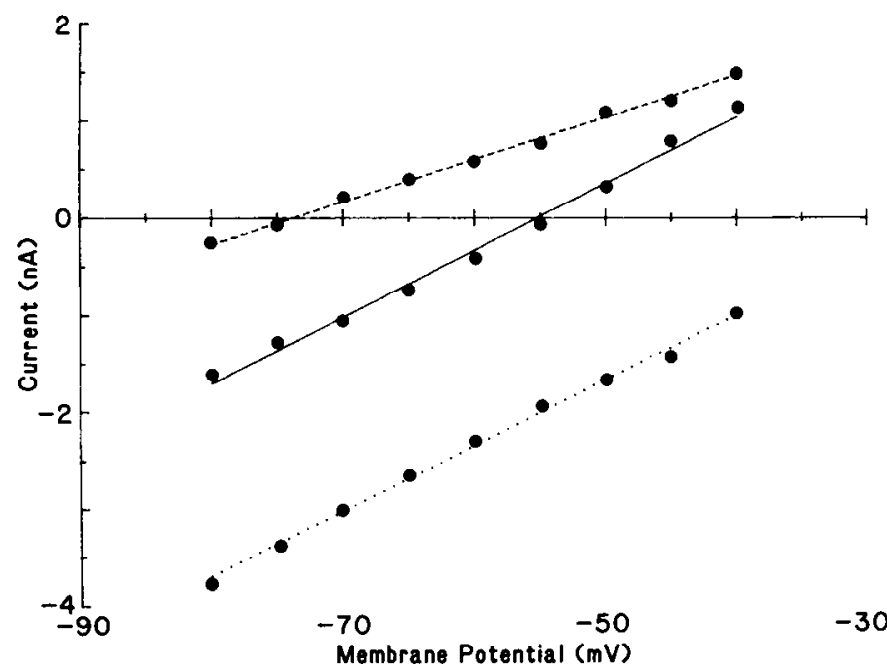

Figure 7. Effect of $\mathrm{K}$ concentration on outward current. Difference $I(V)$ curves measured $40 \mathrm{sec}$ after FMRF-amide application in three different external $\mathrm{K}$ concentrations. In normal ASW $(10 \mathrm{mM} \mathrm{K}$ : solid line), reversal potential $(-55 \mathrm{mV})$ is near that of $I_{A}(-62 \mathrm{mV})$ measured in this cell. In $2 \mathrm{~mm} \mathrm{~K}$ (dashed line), the reversal potential shifted to a more negative value equal to the reversal potential of $-74 \mathrm{mV}$ for $I_{A}$ in this solution. In $50 \mathrm{~mm} \mathrm{~K}$ (dotted line), the reversal potental shifted to a more positive value and by linear extrapolation is approximately $-23 \mathrm{mV}$. The measured $I_{A}$ reversal potential in this solution is -37 $\mathrm{mV}$.
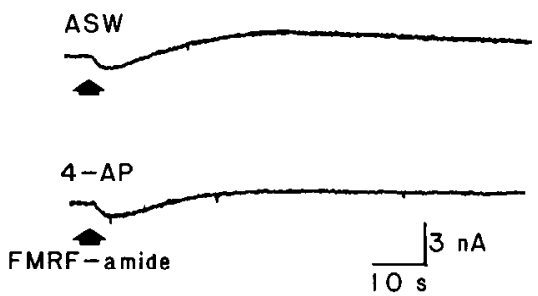

Figure 8. Effects of channel blockers. The outward current response to FMRF-amide was sensitive to 4-AP. Top current record shows the biphasic response to FMRF-amide with the cell in normal ASW. Bottom record shows that $1 \mathrm{~mm} 4$-AP reduced the outward component by a factor of 0.4

pearance of inward ionic current in $\mathrm{L}_{4}$ and $\mathrm{L}_{6}$ is $100-200 \mathrm{msec}$. This is within the range of latencies observed with microapplication of neurotransmitters such as $\mathrm{ACh}$ and serotonin onto Aplysia neuron somata (cf. Kehoe, 1972a; Pellmar and Carpenter, 1980). This latency suggests that FMRF-amide may function as a neurotransmitter to activate ion channels by binding to a receptor that directly gates the channel. The outward current, however, appears after a much longer latency. This result could mean that receptors responsible for the outward current are located away from the site of application. This seems unlikely, however, because the latency and time course are similar with or without continuous perfusion of the bath.

It is possible that that a second messenger might be involved in activating the FMRF-amide induced currents. FMRF-amide has been shown to stimulate the production of cAMP in Aplysia gill tissue (Weiss et al., 1984), a property shared with some neurotransmitters including dopamine (Kebabian et al., 1979).

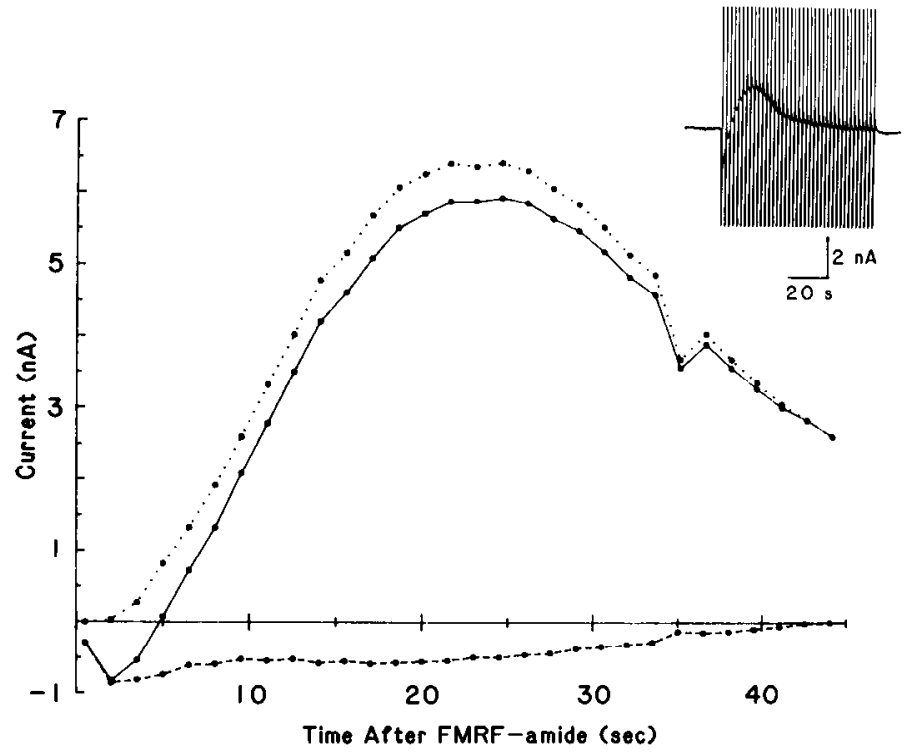

Figure 9. Temporal separation of inward and outward currents. Difference $I(V)$ curves were measured at $1.5 \mathrm{sec}$ intervals following a single FMRF-amide application. The $I(V)$ curve measurement protocol was slightly modified to allow each measurement to be made in $125 \mathrm{msec}$ The contributions of inward (dashed line) and outward (dotted line) currents to the total current (solid line) produced by FMRF-amide were derived algebraically by the method described in the text. The currents are plotted against time after FMRF-amide application. The dip at 36 sec may be due to synaptic input. Inset, Another experiment in which currents were induced by FMRF-amide with the cell voltage clamped at $-40 \mathrm{mV}$. Vertical breaks in the current record indicate the times of rapid $I(V)$ measurements. A 2 sec delay between measurements was necessary in this experiment to allow $I_{A}$ to settle. 
This idea has not been tested in detail, but in preliminary experiments, addition of the adenylcyclase activator forskolin (100 $\mu \mathrm{M})$ to the bathing medium produced no change in the FMRFamide response. Although not definitive, this argues against an involvement of CAMP in the activation of these currents.

The biphasic response to FMRF-amide in $\mathrm{L}_{4}$ and $\mathrm{L}_{6}$ is reminiscent of the multiphasic response to acetylcholine in pleural ganglion ncurons (Kchoc, 1972a, c) and the EIPSP in ccrcbral ganglion neurons to stimulation of histamine-containing presynaptic cells, HNs (McCaman and McKenna, 1978; Weinrich, 1977). It may be that this form of synaptic input is of particular significance to bursting neurons and perhaps other cell types. A series of action potentials leads to cell hyperpolarization in many neurons and this after-hyperpolarization (AHP) is especially pronounced in bursters. An extended period of hyperpolarization may be most effectively accomplished by preceding a hyperpolarizing synaptic input with a depolarization that results in several action potentials. The subsequent AHP can then sum with the inhibitory synaptic input to produce a period of pronounced hyperpolarization.

There are some notable differences between the FMRF-amide response and the responses to $\mathrm{ACh}$ and histamine. One difference is that the biphasic currents caused by FMRF-amide are of longer duration than the EIPSP caused by stimulation of the HNs, although a similar duration was shown for a dopamine response (Kehoe, 1972a). Also, the synaptic response to histaminergic neurons could not be mimicked by application of histamine to the soma of the postsynaptic cell. Only when histamine was applied to the synaptic region of the follower cell in the neuropil could a response be recorded. FMRF-amide, on the other hand, induces a biphasic response when applied directly to the cell body during continuous-bath perfusion. Our application techniques do not completely preclude the diffusion of peptide to synaptic regions. However, as suggested above, this is unlikely because response amplitude is nearly unaffected by bath perfusion.

The reversal potential of the inward current estimated by extrapolation of $I(V)$ curves is consistently more negative than the value expected for a conductance increase purely to $\mathrm{Na}$ ions, but $\mathrm{K}$ currents do not appear to contribute substantially to the early conductance increase (see Fig. 6). The $I(V)$ relationship within the measured voltage range was linear with high correlation coefficients. However, current was measured over a relatively limited voltage range, and slight rectification in the $I(V)$ relationship, which could account for the difference between the measured and expected reversal potentials for the inward current, would not be apparent. Some rectification of the $I(V)$ curve is predicted by the constant field theory (Goldman, 1943; Hodgkin and Katz, 1949) due to asymmetry in Na concentration. A line fit to the $I(V)$ curve predicted by the Goldman-HodgkinKatz current equation for pure $\mathrm{Na}$ conductance for the voltage range between -80 and $-40 \mathrm{mV}$ (assuming $+85 \mathrm{mV}$ as the reversal potential for a $\mathrm{Na}$ current) has an extrapolated reversal potential of $+18.2 \mathrm{mV}$ with a correlation coefficient $>0.99$. We cannot be certain whether such rectification is responsible for the differences between measured and expected reversal potentials.

The changes in reversal potential for both the outward FMRFamide current and $I_{A}$ following changes in external $\mathrm{K}$ concentration are smaller than predicted by the Nernst equation for a purely K-selective process. Such deviations are predicted by the Goldman-Hodgkin-Katz voltage equation for a process with slight permeability to other ions. The outward FMRF-amide current is apparently not as K-selective as the slow ACh-induced IPSP described by Kehoe (1972a). The inward current is slightly activated at the peak of the outward current (see Fig. 9), which may partly account for the incomplete $K$ selectivity of the outward current. It is also possible that a small change in internal
$\mathrm{K}$ concentration follows the change in external $\mathrm{K}$ concentration, resulting in a smaller than expected change in $\mathrm{K}$ driving force.

Stone and Mayeri (1981) reported that FMRF-amide caused hyperpolarization without depolarization in Aplysia neurons $\mathrm{L}_{4}$, $\mathrm{L}_{6}$, and in a number of other left upper quadrant abdominal ganglion neurons. We cannot reconcile these observations with our studies, as we consistently see a biphasic response in these ncurons. In their cxpcriments, peptide was applicd by arterial perfusion. It might be that the slower rate of peptide delivery by this method makes it hard to resolve the depolarizing part of the response or may have produced relatively greater desensitization of the early inward current. They did, however, observe a biphasic response in other neurons with their perfusion technique.

Cottrell (1982) and Cottrell et al. (1984) have shown that the Helix giant serotonergic neuron responds to FMRF-amide and that one component of the response is activation of a voltagedependent $K$ current. At the resting potential the response in Helix was an outward current due to a conductance increase to $\mathrm{K}$. This $\mathrm{K}$ current was blocked by TEA, as was the delayed outward $\mathrm{K}$ current. At more depolarized potentials, there was a second response to FMRF-amide. This was a conductance decrease to a Ca- and voltage-dependent $\mathrm{K}$ current. Cottrell's results differ from ours in several respects. The FMRF-amide response in the neurons we studied was not demonstrably voltage dependent, was mediated by conductance increases first to $\mathrm{Na}$ and then to $\mathrm{K}$, and showed no $\mathrm{Ca}$ dependence, and the conductance increase to $\mathrm{K}$ was not blocked by TEA. Such differences between different cell types and different species are not unexpected.

The differences we observed in time course, dose dependence, and desensitization of the inward and outward currents imply that there may be two distinct receptors associated with the FMRF-amide response in these neurons. The finding that FMRFamide activates two types of ion channels in $\mathrm{L}_{4}$ and $\mathrm{L}_{6}$ and two other responses in the cells studied by Cottrell $(1982,1984)$ means that these responses might be found separately in other neurons, and a spectrum of responses can be expected when FMRF-amide is applied to different cells.

\section{References}

Ascher, P., A. Marty, and T. O. Neild (1978) Life time and elementary conductance of the channels mediating the excitatory effects of acetylcholine in Aplysia neurones. J. Physiol. (Lond.) 278: 177-206.

Barish, M. E., and S. H. Thompson (1983) Calcium buffering and slow recovery kinetics of calcium-dependent outward current in molluscan neurones. J. Physiol. (Lond.) 337: 201-219.

Brown, R. O., A. I. Basbaum, and E. Mayeri (1984) Identification of FMRF-amide immunoreactive neurons in the abominal ganglion of Aplysia. Soc. Neurosci. Abstr. 10: 691.

Cooke, I. M., G. Leblanc, and L. Tauc (1974) Sodium pump stoichiometry in Aplysia neurones from simultaneous current and tracer measurements. Nature 251: 254-255.

Cottrell, G. A. (1982) FMRFamide neuropeptides simultaneously increase and decrease $\mathrm{K}^{+}$currents in an identified neurone. Nature 296 : 87-89.

Cottrell, G. A., Davies, N. W., and K. A. Green (1984) Multiple actions of a molluscan cardioexcitatory neuropeptide and related peptides on identified Helix neurones. J. Physiol. (Lond.) 356: 315-333.

Frazier, W. T., E. R. Kandel, I. Kupfermann, R. Waziri, and R. E. Coggeshall (1967) Morphological and functional properties of identified neurons in the abdominal ganglion of Aplysia californica. $\mathrm{J}$. Neurophysiol. 30: 1288-1351.

Goldman, D. E. (1943) Potential, impedence, and rectification in membranes. J. Gen. Physiol. 27: 37-60.

Hodgkin, A. L., and B. Katz (1949) The effect of sodium ions on the electrical activity of the giant axon of the squid. J. Physiol. (Lond.) 108: 37-77.

Johnson, J. W., and S. H. Thompson (1983) Calcium dependence of resting neuronal conductance. Soc. Neurosci. Abstr. 9: 1187.

Kebabian, P. R., J. W. Kebabian, and D. O. Carpenter (1979) Reg- 
ulation of cyclic AMP in heart and gill by the putative neurotransmitters dopamine and serotonin. Life Sci. 24: 1757-1764.

Kehoe, J. (1972a) Ionic mechanisms of a two component cholinergic inhibition in Aplysia neurones. J. Physiol. (Lond.) 225: 85-1 14.

Kehoe, J. (1972b) Three acetylcholine receptors in Aplysia neurones. J. Physiol. (Lond.) 225: 115-146.

Kehoe, J. (1972c). The physiological role of three acetylcholine receptors in synaptic transmission in Aplysia. J. Physiol. (Lond.) 225: 147-172.

Koester, J., and E. R. Kandel (1977) Further identification of neurons in the abdominal ganglion of Aplysia using behavioral criteria. Brain Res. 121: 1-20.

Kreiger, D. T. (1983) Brain peptides: What, where and why? Science 222: 975-985.

Lehman, H. K., D. A. Price, and M. J. Greenberg (1984) The FMRFamide-like neuropeptide of Aplysia is FMRF-amide. Biol. Bull. 167: 460-466.

McCaman, R. E., and D. G. McKenna (1978) Monosynaptic connections between histamine-containing neurons and their various follower cells. Brain Res. 141: 165-171.

Pellmar, T. C., and D. O. Carpenter (1980) Serotonin induces a voltage sensitive calcium current in neurons of Aplysia californica. J. Neurophysiol. 44: 423-439.
Price, D. A., and M. Greenberg (1977) Purification and characterization of a cardioexcitatory neuropeptide from the central ganglia of a bivalve mollusc. Prep. Biochem. 7: 261-281.

Ruben, P., J. W. Johnson, and S. H. Thompson (1984) Biphasic response of a bursting neuron to FMRF-amide. Soc. Neurosci. Abstr. 10: 1116.

Stone, L. S., and E. Mayeri (1981) Multiple actions of FMRF-amide on identified neurons in the abdominal ganglion of Aplysia. Soc. Neurosci. Abstr. 7: 636 .

Thompson, S. H., and R. W. Aldrich (1980) Membrane potassium channels. In The Cell Surface and Neuronal Function, C. W. Cotman, G. Poste, and G. L. Nicolson, eds., pp. 49-85, Elsevier, Amsterdam.

Walther, C., M. Scheibe, and K. H. Voigt (1984) Synaptic and nonsynaptic effects of molluscan cardioexcitatory neuropeptides on locust skeletal muscle. Neurosci. Lett. 45: 99-104.

Weinrich, D. (1977) Synaptic responses mediated by identified histamine-containing neurones. Nature 267: 854-856.

Weiss, S., J. I. Goldberg, K. S. Chohan, W. K. Stell, G. I. Drummond, and K. Lukowiak (1984) Evidence for FMRF-amide as a neurotransmitter in the gill of Aplysia californica. J. Neurosci. 4: 19942000 . 